\title{
Growth Rate of Lactobacillus ssp. and Streptococcus thermophilus of some Medicinal Plants Water Extracts with Fish Collagen
}

\author{
Yeoh Shin Yong ${ }^{1}$, Teik Jin ${ }^{1}$, Suat Gim ${ }^{1}$, Yeoh Phaik Tin ${ }^{1}$, Keow Joo Nee ${ }^{1}$, Amal Bakr Shori ${ }^{2, *}$, Ahmad \\ Salihin Baba 1 (D) \\ 1 Biomolecular Research Group, Division of Biochemistry, Institute of Biological Sciences, Faculty of Science, University \\ of Malaya, 50603 Kuala Lumpur, Malaysia \\ 2 King Abdulaziz University, Faculty of Science, Department of Biological Sciences, Jeddah 21589, Saudi Arabia \\ * Correspondence: shori_7506@hotmail.com;
}

\begin{abstract}
The main objective of this study was to evaluate the growth rate of Lactobacillus ssp. and Streptococcus thermophilus in 6 types of plant water extract (Lycium barbarum, Illicium verum, Psidium guajava, Curcuma longa, Allium sativum, and Codonopsis pilosula) with two different concentration $(10 \%$ and $2.5 \%$; w/v) both in the presence and absence of fish collagen as a protein source during incubation at $37^{\circ} \mathrm{C}$. The growth rate was measured using a spectrophotometer, and the absorbance was taken every 4 hours for 28 hours (S. thermophilus) and 48 hours (Lactobacillus spp.). The effects of plant water extract on bacterial growth were dose-dependent. The growth of $S$. thermophilus and Lactobacillus spp. in all samples increased with incubation time. After about 12 hours for S. thermophilus in $2.5 \%$ plant extract and 16 hours for other samples with or without fish collagen, it began to plateau. The growth rate of Lactobacillus spp. was significantly higher $(\mathrm{p}<0.05)$ than $S$. thermophilus. Illicium verum and Lycium barbarum, both in the presence and absence of fish collagen, showed the most significant influence of bacterial growth among other samples. Fish collagen had a slight effect on bacteria growth during the incubation period. In conclusion, all plant samples could be an effective vehicle for carrying Lactobacillus ssp. and S. thermophilus.
\end{abstract}

Keywords: Lactobacillus ssp.; S. thermophilus; plants extract; fish collagen; bacterial growth.

(C) 2021 by the authors. This article is an open-access article distributed under the terms and conditions of the Creative Commons Attribution (CC BY) license (https://creativecommons.org/licenses/by/4.0/).

\section{Introduction}

Herbal extracts of traditional medicinal plants have been widely used because of their beneficial health effects, such as lowering blood glucose level and serum lipids, anti-aging, immuno-modulating, anticancer, anti-fatigue, hepatitis, thrombosis, and male fertilityfacilitating [1-6].

Collagen is a major structural protein in the connective tissue of animal skin and bone [7] and is the most abundant protein in animals, comprising approximately $30 \%$ of total proteins [8]. Denatured collagen, known as gelatin, finds applications in the food and biomedical industries [9]. Therefore, fish skin being a byproduct of fish processing, is an important source for collagen production as a replacement for mammalian sources.

Lactic acid bacteria (LAB) is a preparation of viable microorganisms which are added to the diet of humans to control the growth of undesirable or less desirable microorganisms in the gastrointestinal tract, which harbors a rich flora of more than 500 different bacterial species, 
some of which have important health functions [10]. The changes in the population of each species of bacteria are dependent on several factors such as age, diet, healthiness, and use of medications and supplements [11]. The consumption of individual strains of LAB increases the production of antibodies. Previous studies demonstrated that certain LAB can induce specific secretory immunity, and others can enhance the gut inflammatory immune response, Crohn's disease, juvenile chronic arthritis, irritable bowel syndrome, ulcerative colitis, diverticulitis, and chronic pouchitis [12, 13].

For several thousand years, fermentation has been used as an effective and low-cost means to preserve the quality and safety of foods and causes changes in food quality [14]. Fermented non-dairy beverages are the product of the bacterial activity of the starter cultures, resulting in the production of lactic acid and other biologically active compounds with nutritional and therapeutic value [14]. It is essential for LAB to be able to grow progressively in beverage and lactic acid gives the final product its characteristic. There is currently an increasing number of fermented beverages using herbal extract as a natural ingredient [15-17]. Therefore, the main objective of this study was to evaluate the growth rate of Lactobacillus ssp. and Streptococcus thermophilus as starter culture in 6 types of plant water extract (Lycium barbarum, Illicium verum, Psidium guajava, Curcuma longa, Allium sativum, and Codonopsis pilosula) with two different concentration (10\% and $2.5 \%$; w/v) both in the presence and absence of fish collagen as a protein source during incubation at $37^{\circ} \mathrm{C}$.

\section{Materials and Methods}

\subsection{Water extraction of plant.}

Lycium barbarum (LB; dried fruit), Illicium verum (IV; dried fruit), Psidium guajava (PG; dried leaves), Curcuma longa (CL; dried rhizome), Allium sativum (AS; dried fruit), and Codonopsis pilosula (CP; dried root) were purchased in dried form from a local medicinal shop. To prepare $10 \%$ of plant extract, each plant individually $(10 \mathrm{~g})$ was homogenized in sterile distilled water $100 \mathrm{ml}$ using a homogenizer. The mixture was incubated overnight in a water bath $\left(70^{\circ} \mathrm{C}\right)$ followed by centrifugation $\left(15\right.$ minutes, $2000 \mathrm{rpm}$ at $\left.4^{\circ} \mathrm{C}\right)$. The clear supernatant was used as plant water extract. Later, the plant water extract (10\%) was then diluted to $2.5 \%$ by mixing 1 part of the former with 3 parts of $\mathrm{dH}_{2} \mathrm{O}$.

\subsection{Optical density measurement.}

The optical density (OD) using spectrophotometer of increasing microbial mass of bacteria (Lactobacillus ssp. and S. thermophilus) during incubation at $37^{\circ} \mathrm{C}$ was measured in the presence of six types of plants [18] at different concentration (10\% and $2.5 \%$; w/v). $S$. thermophilus or Lactobacillus spp. $(1.0 \mathrm{ml})$ was initially diluted $10 \mathrm{X}$ by mixing in $9 \mathrm{ml}$ sterile peptone water buffer. S. thermophilus $(1 \mathrm{ml})$ was cultured in $28 \mathrm{ml} \mathrm{M} 17$ broth while the Lactobacillus spp. $(1 \mathrm{ml})$ was cultured in MRS broth enriched with lactose. For fish collagen samples, fish collagen $(2.5 \%)$ was added to the broth. Plant water extract ( $1 \mathrm{ml})$ from different concentrations $\left(10 \%\right.$ or $2.5 \%$; w/v) was added to each broth and was then incubated at $37^{\circ} \mathrm{C}$. The control with or without fish collagen was prepared similarly except that plant extract was replaced with distilled water. The absorbance values at $600 \mathrm{~nm}$ of the culture were taken every 4 hours for 28 hours (S. thermophilus) and 48 hours (Lactobacillus spp.) by using the spectrophotometer to see the growth rate of bacteria in different concentration of plant extract. 


\subsection{Statistical analysis.}

This experiment was performed in three different batches $(n=3)$, and the data were expressed as mean \pm S.E.M (mean standard error). The statistical analysis was performed using one-way analysis of variance (ANOVA, SPSS 19.0), followed by Duncan's post hoc test for mean comparison. The criterion for significance was $\mathrm{p}<0.05$.

\section{Results and Discussion}

\subsection{Effects of medicinal plants on the growth rate of S. thermophilus.}

The growth of $S$. thermophilus in the presence of 6 different types of plant water extracts $(2.5 \%$ and $10 \%$; w/v) during 28 hours was shown in Figures $1 \mathrm{a} \& \mathrm{~b}$, respectively. The growth of $S$. thermophilus in all samples increased with incubation time and generally began to plateau after about 12-28 hours for 2.5\% and 16-28 hours for 10\% of plant extract (Figure 1a \& b). At the beginning, S. thermophilus showed higher $(\mathrm{p}<0.05)$ growth in both $2.5 \%$ and $10 \% \mathrm{PG}$ and CL with $\mathrm{OD}_{600}$ of $0.41 \& 0.45$ for $2.5 \%$ and $0.72 \& 0.62$ for $10 \%$; respectively while control had $\mathrm{OD}_{600}=0.32$. Other plant extracts $(2.5 \%)$ showed no significant differences in the growth of S. thermophilus. However, CP, AS, IV, and LB (2.5\%) showed significant growth of $S$. thermophilus $\left(\mathrm{OD}_{600}=1.4-0.5\right)$ compared to control $\left(\mathrm{OD}_{600}=1.2\right)$ after 12 hours. PG extract (2.5\%) inhibited the growth of S. thermophilus from 16 to 28 hours (Figure 1a). All plant extracts $(10 \%)$ except CL registered increase $(\mathrm{p}<0.05)$ in the growth of $S$. thermophilus, with the highest value, was shown for PG followed by LB, CP, IV, and AS at 12 hours (Figure 1b). CL extract $(10 \%)$ showed lower $(\mathrm{p}<0.05)$ growth of $S$. thermophilus from 8 to 24 hours. At the end of incubation, there were no significant differences between all $10 \%$ samples as compared to control (Figure 1b).

In the presence of fish collagen, the growth of $S$. thermophilus in plants extracts began to plateau at a much later time (16-28 hours) for both $2.5 \%$ and $10 \%$ of plant extract (Figure 2 a \& b). Generally, the presence of fish collagen in $10 \%$ of plant extracts improved the growth of $S$. thermophilus throughout incubation time (Figure $2 b$ ). At the beginning of incubation, the presence of fish collagen in $2.5 \%$ and $10 \%$ of CL and PG water extracts significantly stimulated the growth of $S$. thermophilus $\left(\mathrm{OD}_{600}=0.41 \& 0.55\right.$ for $2.5 \%$ and $0.63 \& 0.91$ for $10 \%$; respectively ) compared to control $\left(\mathrm{OD}_{600}=0.32\right.$; Figure $\left.2 \mathrm{a} \& \mathrm{~b}\right)$. Plants extract $(2.5 \%)$ with fish collagen such as CP, PG, IV, and LB showed higher $(\mathrm{p}<0.05)$ growth of $S$. thermophilus than control with the highest value was seen in $\mathrm{LB}+\mathrm{FC}\left(\mathrm{OD}_{600}=0.89\right)$ at 4 hours. These values were continuing to increase until 12 hours where $\mathrm{PG}+\mathrm{FC}$ recorded the highest growth $\left(\mathrm{OD}_{600}=\right.$ 1.68). Both CL and AS + FC showed lower S. thermophilus growth than control from 4 to 24 hours (Figure 2a). On the other hand, 10\% IV and LB+ FC increased ( $\mathrm{p}<0.05)$ S. thermophilus growth from 4-20 hours, whereas CL and PG+ FC stimulated bacteria growth all over the incubation period (Figure $2 b$ ). There was no significant difference in bacteria growth in $10 \%$ $\mathrm{CP}+\mathrm{FC}$ than control during incubation except at 8 hours (Figure 2b).

\subsection{Effects of medicinal plants on the growth rate of Lactobacillus spp.}

The stimulatory effects on Lactobacillus spp. growth was tremendously enhanced ( $\mathrm{p}<0.05$ ) by $2.5 \% \mathrm{CP}, \mathrm{IV}, \mathrm{LB}$, and AS compared to control with OD600 ranged between 2.2 and 2.3 at 44 hours (Figure 3a). However, PG and CL decreased $(\mathrm{p}<0.05)$ the bacterial growth $\left(\mathrm{OD}_{600}=0.85-1.59\right.$ and $1.15-1.16$ for $\mathrm{PG}$ and $\mathrm{CL}$; respectively $)$ as compared to control $\left(\mathrm{OD}_{600}=\right.$ 
1.5-1.8) from 12 to 20 hours of incubation. At the end of incubation, all plant extract showed no significant differences in Lactobacillus spp. growth compared to control except for PG and $\mathrm{CL}$ that showed a significant reduction in the growth (Figure 3a). Increasing the concentration $(10 \%)$ of plant extract had a significant effect on the bacterial growth during 40 hours of incubation periods at the following order AS $>\mathrm{CL}>\mathrm{PG}=\mathrm{CP}>\mathrm{IV}>\mathrm{LB}$ (Figure 3b). Extending incubation to 2 days had no effects on the bacterial growth.

The inclusion of fish collagen in the $2.5 \%$ plant extract displayed no significant effects on Lactobacillus spp. growth for all samples except at earlier stages for CP, PG, IV, and LB (Figure 4a). Similarly, 10\% of plant extract with fish collagen had little effect in stimulating Lactobacillus spp's growth compared to control (Figure 4b). At an earlier stage, CP, IV, and LB showed a significant increase in bacterial growth $\left(\mathrm{OD}_{600}=\sim 1.9\right)$ compared to control $\left(\mathrm{OD}_{600}=1.7\right)$ at 12 hours of incubation. In addition, $\mathrm{AS}+\mathrm{FC}$ showed the highest $(\mathrm{p}<0.05)$ bacterial growth $\left(\mathrm{OD}_{600}=2.38\right)$ at 40 hours while $\mathrm{PG}+\mathrm{FC}$ had the highest growth $\left(\mathrm{OD}_{600}=\right.$ $2.30)$ at 48 hours. $\mathrm{CL}+\mathrm{FC}$ showed higher Lactobacillus spp. growth $\left(\mathrm{OD}_{600}=2.59 ; \mathrm{p}<0.05\right)$ than control $\left(\mathrm{OD}_{600}=2.24\right)$ at 28 hours.

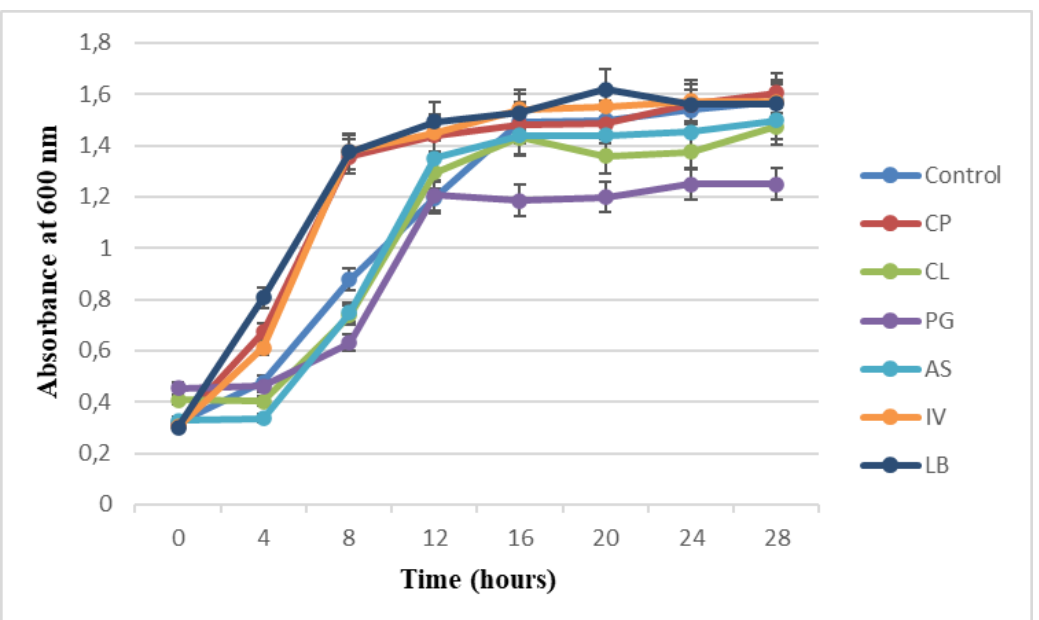

Figure 1a. The growth rate of Streptococcus thermophilus in $2.5 \%$ plant extract during incubation at $37^{\circ} \mathrm{C}$ for 28 hours. $\mathrm{LB}=$ Lycium barbarum, $\mathrm{IV}=$ Illicium verum, $\mathrm{PG}=$ Psidium guajava, $\mathrm{CL}=$ Curcuma longa, $\mathrm{AS}=$ Allium sativum, and $\mathrm{CP}=$ Codonopsis pilosula. Control= medium suspension without plant extract.

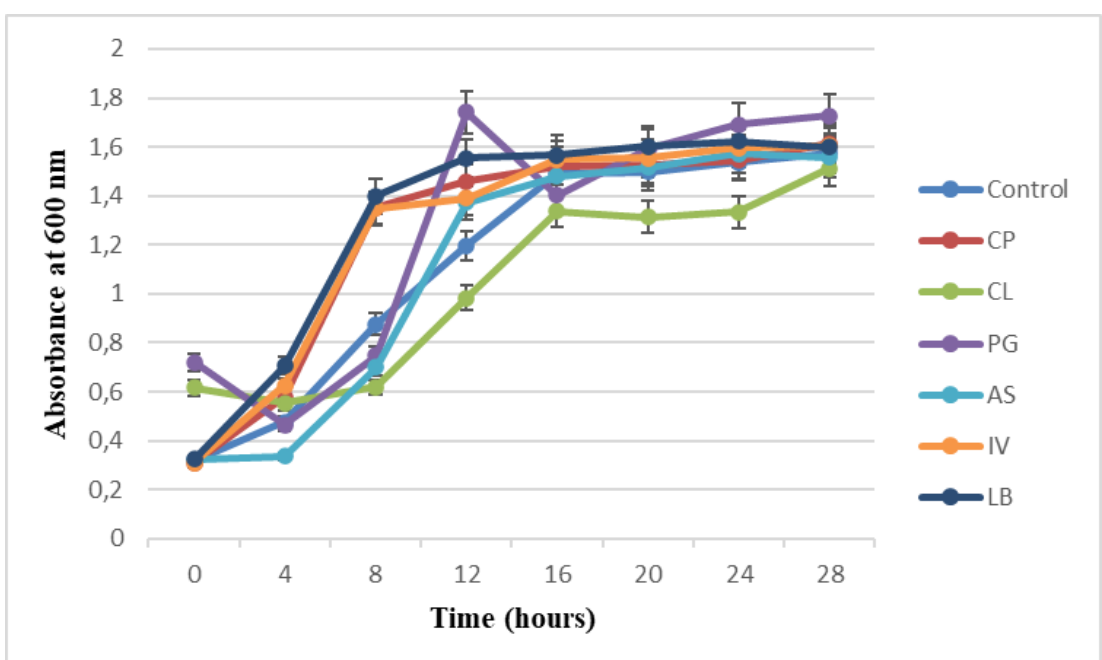

Figure 1b. The growth rate of Streptococcus thermophilus in $10 \%$ plant extract during incubation at $37^{\circ} \mathrm{C}$ for 28 hours. $\mathrm{LB}=$ Lycium barbarum, $\mathrm{IV}=$ Illicium verum, $\mathrm{PG}=$ Psidium guajava, $\mathrm{CL}=$ Curcuma longa, $\mathrm{AS}=$ Allium sativum, and $\mathrm{CP}=$ Codonopsis pilosula . $\mathrm{Control}=$ medium suspension without plant extract. 


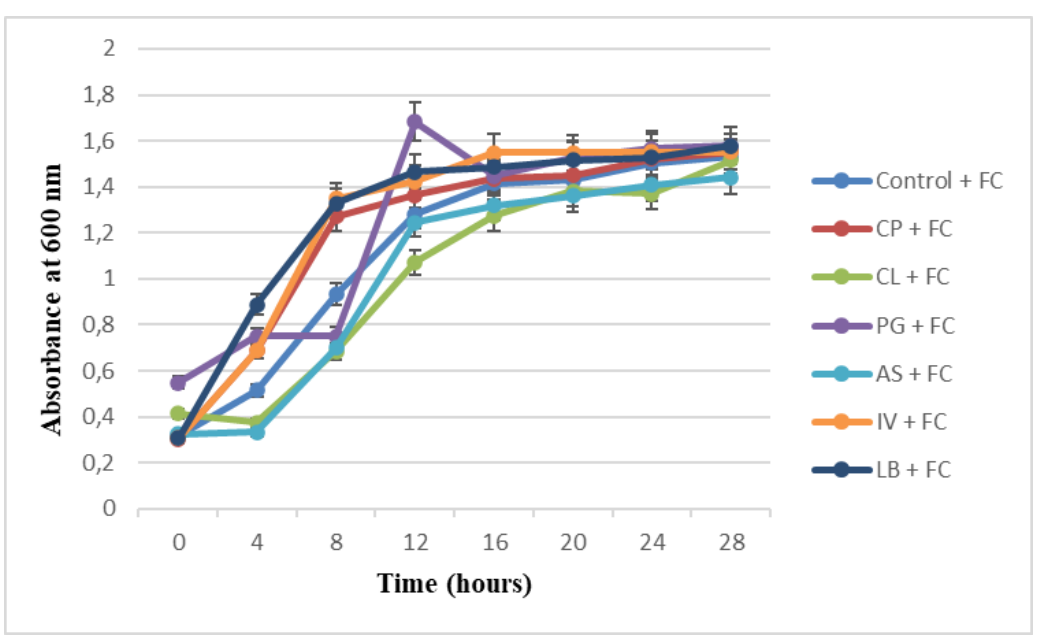

Figure 2a. The growth rate of Streptococcus thermophilus in 2.5\% plant extract with fish collagen during incubation at $37^{\circ} \mathrm{C}$ for 28 hours. $\mathrm{LB}=$ Lycium barbarum, $\mathrm{IV}=$ Illicium verum, $\mathrm{PG}=$ Psidium guajava, $\mathrm{CL}=$ Curcuma longa, $\mathrm{AS}=$ Allium sativum, and $\mathrm{CP}=$ Codonopsis pilosula . Control= medium suspension without plant extract.

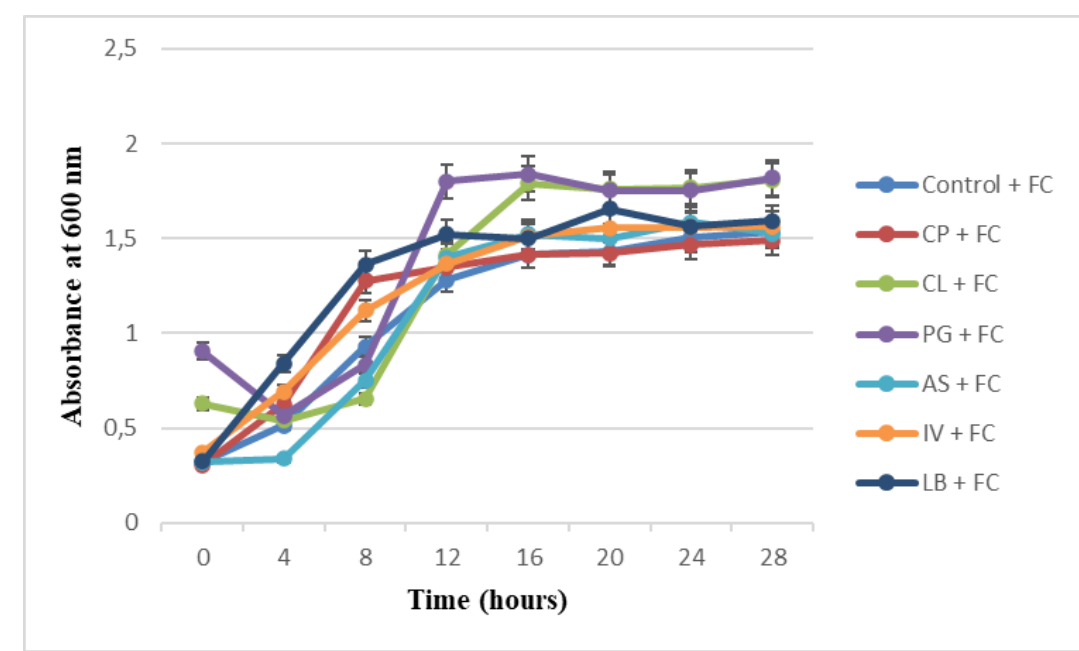

Figure 2b. The growth rate of Streptococcus thermophilus in 10\% plant extract with fish collagen during incubation at $37^{\circ} \mathrm{C}$ for 28 hours. $\mathrm{LB}=$ Lycium barbarum, IV=Illicium verum, $\mathrm{PG}=$ Psidium guajava, $\mathrm{CL}=$ Curcuma longa, $\mathrm{AS}=$ Allium sativum, and $\mathrm{CP}=$ Codonopsis pilosula . Control= medium suspension without plant extract.

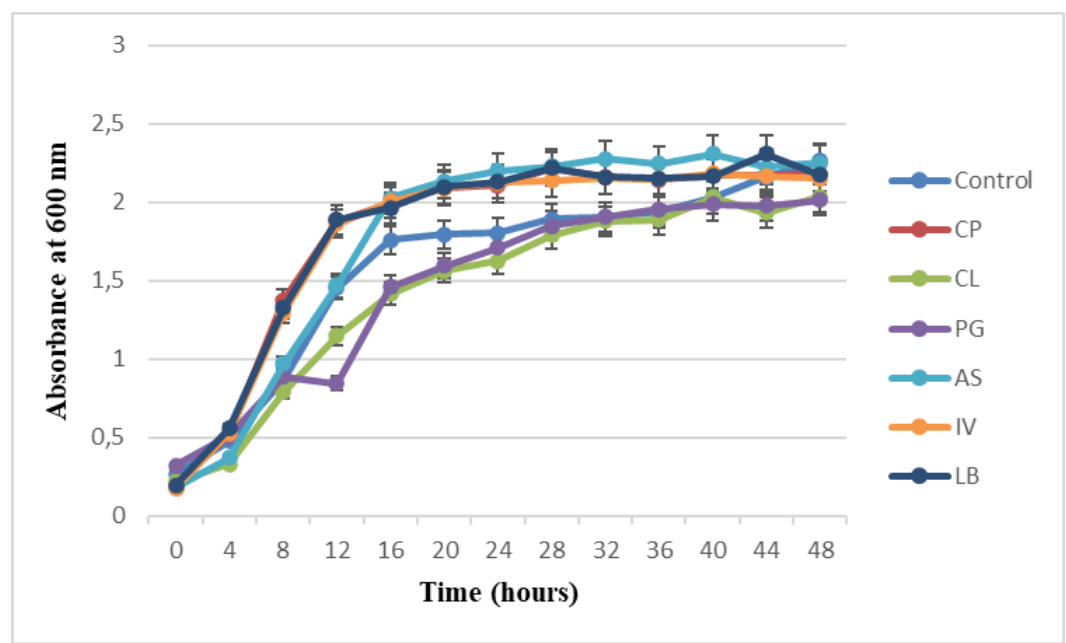

Figure 3a. The growth rate of Lactobacillus spp. in $2.5 \%$ plant extract during incubation at $37^{\circ} \mathrm{C}$ for 48 hours. $\mathrm{LB}=$ Lycium barbarum, $\mathrm{IV}=$ Illicium verum, $\mathrm{PG}=$ Psidium guajava, $\mathrm{CL}=$ Curcuma longa, $\mathrm{AS}=$ Allium sativum, and $\mathrm{CP}=$ Codonopsis pilosula . $\mathrm{Control}=$ medium suspension without plant extract. 


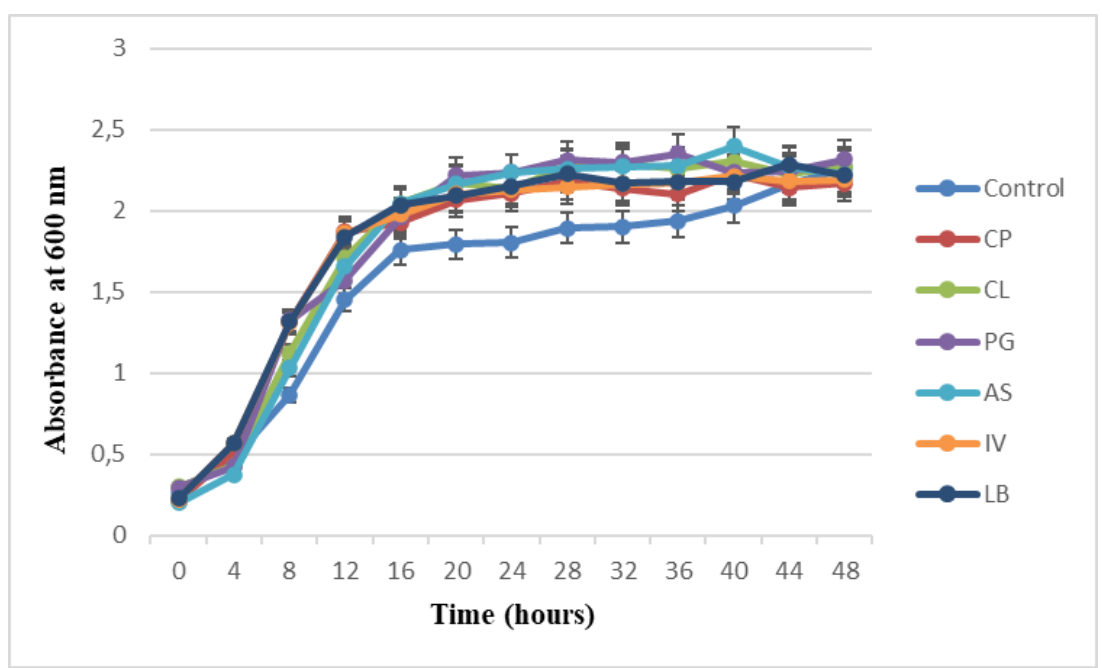

Figure 3b. The growth rate of Lactobacillus spp. in $10 \%$ plant extract during incubation at $37^{\circ} \mathrm{C}$ for 48 hours. $\mathrm{LB}=$ Lycium barbarum, $\mathrm{IV}=$ Illicium verum, $\mathrm{PG}=$ Psidium guajava, $\mathrm{CL}=$ Curcuma longa, $\mathrm{AS}=$ Allium sativum, and $\mathrm{CP}=$ Codonopsis pilosula . Control= medium suspension without plant extract.

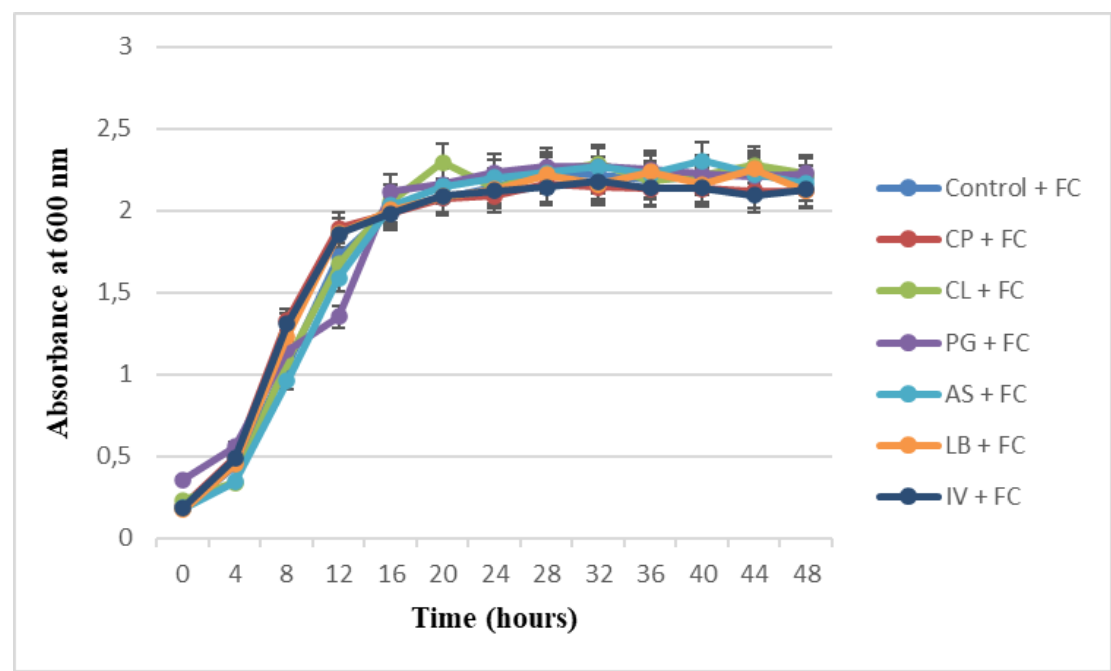

Figure 4a. The growth rate of Lactobacillus spp. in $2.5 \%$ plant extract with fish collagen during incubation at $37^{\circ} \mathrm{C}$ for 48 hours. $\mathrm{LB}=$ Lycium barbarum, $\mathrm{IV}=$ Illicium verum, $\mathrm{PG}=$ Psidium guajava, $\mathrm{CL}=$ Curcuma longa,

$\mathrm{AS}=$ Allium sativum, and $\mathrm{CP}=$ Codonopsis pilosula . Control= media without plant extract.

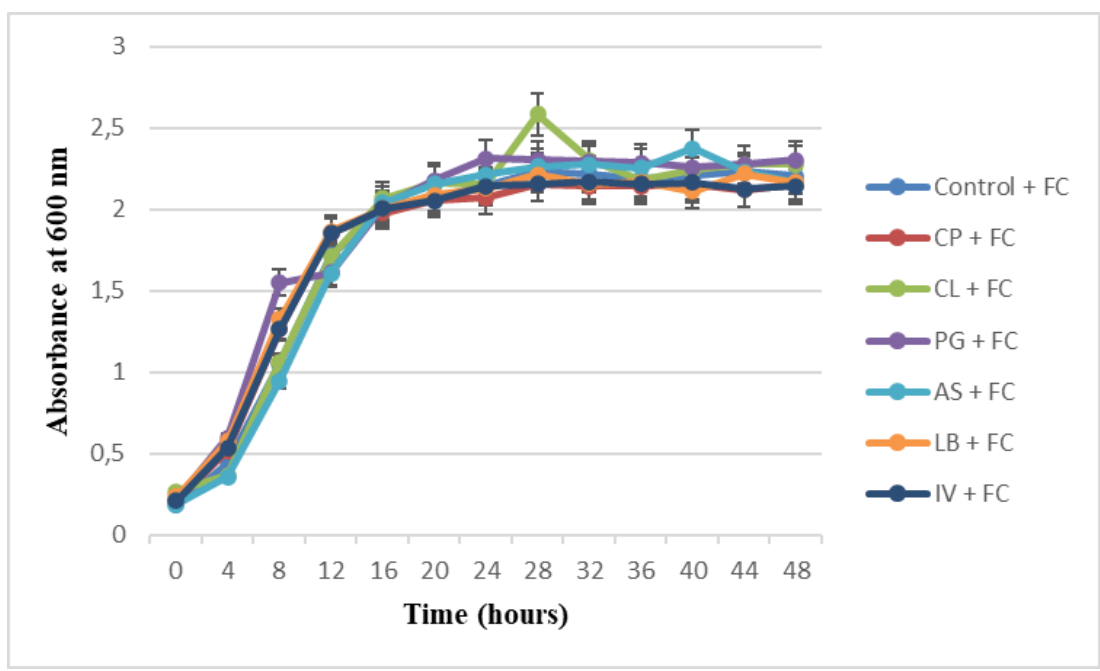

Figure 4b. The growth rate of Lactobacillus spp. in $10 \%$ plant extract with fish collagen during incubation at $37^{\circ} \mathrm{C}$ for 48 hours. $\mathrm{LB}=$ Lycium barbarum, $\mathrm{IV}=$ Illicium verum, $\mathrm{PG}=$ Psidium guajava, $\mathrm{CL}=$ Curcuma longa, $\mathrm{AS}=$ Allium sativum, and $\mathrm{CP}=$ Codonopsis pilosula . Control= media without plant extract. 


\subsection{Discussion.}

Optical density (OD), also known as turbidity or absorbance, can be used to measure the concentration of bacteria in a suspension because the amount of light absorbed by a suspension of cells, within limits, is proportional to biomass [19]. Most of the effects of plant water extract on bacterial growth were dose-dependent. This was seen for the growth of $S$. thermophilus, which has higher growth at $10 \%$ concentration of plant extract both in the presence and absence of fish collagen than $2.5 \%$ concentration for all the samples. This might occur because the high concentration of plant extracts could influence bacteria's growth by enhancing their metabolic activity $[2,14]$. On the other hand, the inhibitory effects on the growth of $S$. thermophilus occurred in the presence of CL (2.5\% and $10 \%)$, PG (2.5\%), CL, and AS + FC (2.5\%; Figure 1a\&b, 2a). Several factors contributed to the changes in OD during incubation, and this includes $\mathrm{pH}$ and temperature [20], glucose [21], and metabolic stress factors (lactic acid, acetic acid, and hydrogen peroxide; [22, 23]). Apart from natural plant dyes which directly affect the colorimetric absorbance [24]. Plants water extract showed stimulatory effects on Lactobacillus spp. growth at a higher amount (10\%). The plant water extracts may contribute a varying amount of phytochemicals that directly affect bacteria's growth and metabolism [2, 14]. IV and LB, both in the presence and absence of fish collagen, significantly influenced the bacterial growth during the incubation time. This could be attributed to active constituents in plants $[2,14]$. L. barbarum polysaccharide (LBP) such as glucose, galactose, arabinose, rhamnose, mannose, and xylose in LBP can stimulate $S$. thermophilus and Lactobacillus spp. growth in fermented foods [25-27]. There is no available information about the effects of I. verum on the growth of S. thermophilus and Lactobacillus spp. During fermentation. Although the addition of fish collagen in fermented milk provides an additional source of available protein for LAB growth [28-30], the present results indicated that fish collagen had a slight effect on bacteria growth during the incubation period.

\section{Conclusions}

The effects of plant water extract on bacterial growth were dose-dependent. The concentration of plant water extract $(10 \%)$ showed higher bacterial growth than $2.5 \%$. The growth of $S$. thermophilus in all samples increased with incubation time and generally began to plateau after about 12 hours for $2.5 \%$ plant extract and 16 hours for other samples with or without fish collagen. Similarly, the growth of Lactobacillus spp. began to plateau after about 16 hours for all samples. The growth rate of Lactobacillus spp. was significantly higher than S. thermophilus. IV and LB, both in the presence and absence of fish collagen, showed the most significant bacterial growth influence among other samples. Fish collagen had a slight effect on bacteria growth during the incubation period. All plant samples could be an effective vehicle for carrying Lactobacillus ssp. and S. thermophilus.

\section{Funding}

This research received no external funding.

\section{Acknowledgments}

This research has no acknowledgment. 


\section{Conflicts of Interest}

\section{The authors declare no conflict of interest.}

\section{References}

1. Shori, A.B.; Baba, A.S.; Keow, J.N. Effect of Allium sativum and fish collagen on the proteolytic and angiotensin-I converting enzyme-inhibitory activities in cheese and yogurt. Pakistan Journal of Biological Sciences 2012, 15, 1160-1167, https://doi.org/10.3923/pjbs.2012.1160.1167.

2. Shori, A.B. Screening of antidiabetic and antioxidant activities of medicinal plants. Journal of Integrative Medicine 2015, 13, 297-305, https://doi.org/10.1016/S2095-4964(15)60193-5.

3. Gan, L.; Hua Zhang, S.; Liang Yang, X.; Bi Xu, H. Immunomodulation and antitumor activity by a polysaccharide-protein complex from Lycium barbarum. International Immunopharmacology 2004, 4, 563569, https://doi.org/10.1016/j.intimp.2004.01.023.

4. Guo, W.; Tan, H.-Y.; Chen, F.; Wang, N.; Feng, Y. Targeting Cancer Metabolism to Resensitize Chemotherapy: Potential Development of Cancer Chemosensitizers from Traditional Chinese Medicines. Cancers 2020, 12, https://doi.org/10.3390/cancers12020404.

5. Peng, X.; Tian, G. Structural characterization of the glycan part of glycoconjugate LbGp2 from Lycium barbarum L. Carbohydrate Research 2001, 331, 95-99, https://doi.org/10.1016/s0008-6215(00)00321-9.

6. Wang, Y.; Zhao, H.; Sheng, X.; Gambino, P.E.; Costello, B.; Bojanowski, K. Protective effect of Fructus Lycii polysaccharides against time and hyperthermia-induced damage in cultured seminiferous epithelium. Journal of Ethnopharmacology 2002, 82, 169-175, https://doi.org/10.1016/s0378-8741(02)00169-1.

7. Liu, X.; Zheng, C.; Luo, X.; Wang, X.; Jiang, H. Recent advances of collagen-based biomaterials: Multihierarchical structure, modification and biomedical applications. Materials Science and Engineering: $C$ 2019, 99, 1509-1522, https://doi.org/10.1016/j.msec.2019.02.070.

8. Muyonga, J.H.; Cole, C.G.B.; Duodu, K.G. Extraction and physico-chemical characterisation of Nile perch (Lates niloticus) skin and bone gelatin. Food Hydrocolloids 2004, 18, 581-592, https://doi.org/10.1016/J.FOODHYD.2003.08.009.

9. Anand, S.; Kamath, S.; Chuang, L.; Kasapis, S.; Lopata, A.L. Biochemical and thermo-mechanical analysis of collagen from the skin of Asian Sea bass (Lates calcarifer) and Australasian Snapper (Pagrus auratus), an alternative for mammalian collagen. European Food Research and Technology 2013, 236, 873-882, https://doi.org/10.1007/s00217-013-1950-9.

10. Shori, A.B. The potential applications of probiotics on dairy and non-dairy foods focusing on viability during storage. Biocatalysis and Agricultural Biotechnology 2015, 4, 423-431, https://doi.org/10.1016/j.bcab.2015.09.010.

11. Miller, L.E.; Lehtoranta, L.; Lehtinen, M.J. Short-term probiotic supplementation enhances cellular immune function in healthy elderly: systematic review and meta-analysis of controlled studies. Nutrition Research 2019, 64, 1-8, https://doi.org/10.1016/j.nutres.2018.12.011.

12. Ouwehand, A.C.; Salminen, S.; Isolauri, E. Probiotics: an overview of beneficial effects. Antonie van Leeuwenhoek 2002, 82, 279-289, https://doi.org/10.1023/a:1020620607611.

13. Roberts, A.; Barrangou, R. Applications of CRISPR-Cas systems in lactic acid bacteria. FEMS Microbiology Reviews 2020, 44, 523-537, https://doi.org/10.1093/femsre/fuaa016.

14. Shori, A.B. Influence of food matrix on the viability of probiotic bacteria: A review based on dairy and nondairy beverages. Food Bioscience 2016, 13, 1-8, https://doi.org/10.1016/j.fbio.2015.11.001.

15. Paul, A.A.; Kumar, S.; Kumar, V.; Sharma, R. Milk Analog: Plant based alternatives to conventional milk, production, potential and health concerns. Critical Reviews in Food Science and Nutrition 2020, 60, 30053023, https://doi.org/10.1080/10408398.2019.1674243.

16. Garcia, C.; Guerin, M.; Souidi, K.; Remize, F. Lactic Fermented Fruit or Vegetable Juices: Past, Present and Future. Beverages 2020, 6, https://doi.org/10.3390/beverages6010008.

17. Emiljanowicz, K.E.; Malinowska-Pańczyk, E. Kombucha from alternative raw materials - The review. Critical Reviews in Food Science and Nutrition 2020, 60, 3185-3194, https://doi.org/10.1080/10408398.2019.1679714.

18. Sher, S.; Hussain, S.Z.; Rehman, A. Phenotypic and genomic analysis of multiple heavy metal-resistant Micrococcus luteus strain AS2 isolated from industrial waste water and its potential use in arsenic bioremediation. Applied Microbiology and Biotechnology 2020, 104, 2243-2254, https://doi.org/10.1007/s00253-020-10351-2.

19. Rajnovic, D.; Muñoz-Berbel, X.; Mas, J. Fast phage detection and quantification: An optical density-based approach. PLOS ONE 2019, 14, https://doi.org/10.1371/journal.pone.0216292.

20. Olukomaiya, O.O.; Adiamo, O.Q.; Fernando, W.C.; Mereddy, R.; Li, X.; Sultanbawa, Y. Effect of solidstate fermentation on proximate composition, anti-nutritional factor, microbiological and functional properties of lupin flour. Food Chemistry 2020, 315, https://doi.org/10.1016/j.foodchem.2020.126238.

21. Sriputorn, B.; Laopaiboon, P.; Phukoetphim, N.; Polsokchuak, N.; Butkun, K.; Laopaiboon, L. Enhancement of ethanol production efficiency in repeated-batch fermentation from sweet sorghum stem juice: Effect of 
initial sugar, nitrogen and aeration. Electronic Journal of Biotechnology 2020, 46, 55-64, https://doi.org/10.1016/j.ejbt.2020.06.001.

22. Gao, L.; Wu, X.; Zhu, C.; Jin, Z.; Wang, W.; Xia, X. Metabolic engineering to improve the biomanufacturing efficiency of acetic acid bacteria: advances and prospects. Critical Reviews in Biotechnology 2020, 40, 522538, https://doi.org/10.1080/07388551.2020.1743231.

23. Lourenço, A.; Pedro, N.A.; Salazar, S.B.; Mira, N.P. Effect of Acetic Acid and Lactic Acid at Low pH in Growth and Azole Resistance of Candida albicans and Candida glabrata. Frontiers in Microbiology 2019, 9 , https://doi.org/10.3389/fmicb.2018.03265.

24. Martín-Tornero, E.; de Jorge Páscoa, R.N.M.; Espinosa-Mansilla, A.; Martín-Merás, I.D.; Lopes, J.A. Comparative quantification of chlorophyll and polyphenol levels in grapevine leaves sampled from different geographical locations. Scientific Reports 2020, 10, 1-13. https://doi.org/10.1038/s41598-020-63407-8.

25. Skenderidis, P.; Mitsagga, C.; Lampakis, D.; Petrotos, K.; Giavasis, I. The Effect of Encapsulated Powder of Goji Berry (Lycium barbarum) on Growth and Survival of Probiotic Bacteria. Microorganisms 2020, 8, https://doi.org/10.3390/microorganisms8010057.

26. Zhou, Y.; Cui, Y.; Qu, X. Exopolysaccharides of lactic acid bacteria: Structure, bioactivity and associations: A review. Carbohydrate Polymers 2019, 207, 317-332, https://doi.org/10.1016/j.carbpol.2018.11.093.

27. Ding, Y.; Yan, Y.; Peng, Y.; Chen, D.; Mi, J.; Lu, L.; Luo, Q.; Li, X.; Zeng, X.; Cao, Y. In vitro digestion under simulated saliva, gastric and small intestinal conditions and fermentation by human gut microbiota of polysaccharides from the fruits of Lycium barbarum. International Journal of Biological Macromolecules 2019, 125, 751-760, https://doi.org/10.1016/j.ijbiomac.2018.12.081.

28. Shori, A.B. Changes of hemoglobin content and glucose levels in the blood of Rattus norvegicus by water extracts of Azadirachta indica. Chinese Journal of Natural Medicines 2012, 10, 135-137, https://doi.org/10.3724/SP.J.1009.2012.00135.

29. Shori, A.B.; Baba, A.S.; Chuah, P.F. The effects of fish collagen on the proteolysis of milk proteins, ACE inhibitory activity and sensory evaluation of plain- and Allium sativum-yogurt. Journal of the Taiwan Institute of Chemical Engineers 2013, 44, 701-706, https://doi.org/10.1016/j.jtice.2013.01.024.

30. Shori, A.B.; Baba, A.S.; Hoen Solear, L.S. Allium sativum and fish collagen enhanced proteolysis pattern of milk protein during cheddar cheese ripening. Journal of Agriculture and Food Research 2020, 2, https://doi.org/10.1016/j.jafr.2020.100059. 